\title{
TCO and back contact buffer significance to achieve highest open circuit voltage and efficiency of CdTe solar cells
}

\author{
Bablu K. Ghosh ( $\sim$ ghoshbab@ums.edu.my) \\ Universiti Malaysia Sabah https://orcid.org/0000-0003-1457-3646 \\ Ismail Saad \\ University Malaysia Sabah \\ Khairul A Mahmood \\ UTHM
}

\section{Research Article}

Keywords: CdTe, TCO, ZnO, SnO2, back surface field, open circuit voltage, efficiency

Posted Date: March 11th, 2021

DOI: https://doi.org/10.21203/rs.3.rs-269604/v1

License: (1) (i) This work is licensed under a Creative Commons Attribution 4.0 International License.

Read Full License 


\section{Abstract}

CdTe thin film (TF) solar cells are most promising in commercial stage photovoltaic (PV) technologies. Cell contacts and interface defects related opto-electrical losses are still vital to limit its further technological benefit. Thin film PV cells shallow recombination and parasitic loss lessening purpose carrier selective back contact selection with band matching interface layers are essential. Beside that layer thickness selection is vital for field assisted selective carrier collection. The suitable emitter and buffer layer selection with band gap matching to the active layer can lessen parasitic absorption loss. In this purpose SCAPS software based $\mathrm{ZnO}$ and $\mathrm{SnO}_{2} \mathrm{TCO}$ as well as $\mathrm{CdS}$ and CdSe buffer impact are numerically analyzed. The TCO, emitter, back surface field and metal contacts effects on electrical performance is studied. In the model, TCO and back contact barrier thickness is shown significant to progress electrical performance. Eventually, open circuit voltage $\mathrm{Voc}=0.9757 \mathrm{~V}$ and $19.92 \%$ efficiency is achieved for $90 \mathrm{~nm}$ of ZnTe BSF with ZnO TCO and CdS emitter layer of optimized thickness.

\section{Highlights}

- CdTe TF HJ solar cell back buffer contact and TCO significance is revealed.

- CdSe emitter higher Jsc but less Voc in comparison to CdS is realized.

- Back contact thickness effect on Voc and efficiency progression is presented.

- $\mathrm{CdS} / \mathrm{CdTe} \mathrm{HJ}$ Voc $=0.9757 \mathrm{~V}$ and efficiency $19.92 \%$ is attained for $90 \mathrm{~nm} \mathrm{ZnTe}$ buffer .

\section{Introduction}

Climate change and global warming effect mitigation purpose renewable energy technologies massive implementation is substantial. As wide research achievements and industrial developed renewable energy technology, inorganic solar photovoltaic (SPV) efficiency progression is still demanding to make it more client and production favor in energy sector. Most marketable solar photovoltaic advancement pathways towards selective contact design for less opto-electrical losses are pondered in our recent review [1]. Industrial $\mathrm{Si}$ and $\mathrm{CdTe}$ solar cells are possessed least energy payback time as it can be seen from Fig. 1. Worldwide development of Si and CdTe based PV technologies and their global advancement are also reported by Fraunhofer ISE research institute in 2020 [2]. Carrier-selective (CS) Si hetero-junction $(\mathrm{SHJ})$ solar cells passivation schemes are essential for advancement in contact design and increasing open circuit voltage [3].

Affording performance benefits well-designed back passivation contacts by replacing direct metallic contact is robust to improve Voc. p-type CdTe work function and majority carrier matching purpose innovative back surface field (BSF) layer design is vital. The optical loss lessening and current density increasing purpose TCO layer thickness selection is potential that can maximize the acceptor-donor carrier accumulation at the junction [4]. However it can reaches the efficiency level $<16 \%$. Not only shallow recombination lessening, Si technology alike profound CS and BSF design is significant to 
improve CdTe cell Voc and efficiency. The CdTe TFPV electron barrier design purpose proper BSF and work function metal contact is impending for higher fill factor (FF) thus efficiency can be increased. However, interface shallow depletion area with buffer layer for CdTe thin film solar cell is enhanced recombination as a result $\mathrm{Voc}$ and $\mathrm{FF}$ is minimized. To overcome these difficulties researchers are trying to adept new design technologies to improve back contact electron barrier and majority carrier lifetime to achieve highest efficiency [5-6]. Though theoretical design is shown highest efficiency but practical efficiency progression is still an impediment. Majority carrier lifetime domain CdTe cell back barrier effect and p-contact metal selection is important to improve overall performance [7]. Though CdTe/ZnTe:Cu/Au contact has improved interface and electrical performance but $V o c$ is decreased linearly with increase temperature. It has possible relation of Cu diffusion towards $\mathrm{ZnTe} / \mathrm{CdTe}$ interface. Even efficiency at room temperature is shown to decrease nearly $16 \%$ at $\mathrm{Voc}=0.82 \mathrm{~V}$ and highest $75 \% \mathrm{FF}$ is shown. From earlier CdTe/ZnTe design [8-9] and present significance of very recent study [7]; it is recognized that not only ZnTe BSF for Voc but the metal and BSF contact can optimize the FF that is potential for efficiency progression. The front TCO and emitter design has also importance on Voc, and current density. The external quantum efficiency (EQE) development purposes both front and back proper interface design is vital. Therefore, CdTe profound TCO, emitter as well as back buffer and metal contact is developed by SCAPS simulation software. Finally the TCO, emitters with ZnTe BSF and Cu or Mo contact effect in energy conversion efficiency and EQE is numerically analyzed in this work. The Voc $=0.9757 \mathrm{~V}$ and $19.92 \%$ efficiency is achieved for $>84 \%$ FF of the optimized device.

\section{Methodology}

Opto-electric design purpose SCAPS software based CdTe thin film hetero-junction (HJ) front TCO, emitter and back contacts are designed and modeling. Aim to improve electrical performance of CdTe cell, the back metal contact with $\mathrm{Cu}$ and $\mathrm{Mo}$ is analyzed for the specific TCO, emitter and BSF layer of their optimized thickness.

\subsection{CdTe HJ model}

CdTe PV cell design and development is performed by SCAPS modeling software. SCAPS is commonly used for thin film solar cells designed. The configuration is fixed to superstrate type that arrangement comprises of six layers which are transmission solar glass, higher band gap $\mathrm{ZnO}$ or $\mathrm{SnO}_{2}$ used as a transparent conductive oxide (TCO) layer, CdS/CdSe as an emitter layer, the CdTe as absorber layer, ZnTe as BSF and the back metal ( $\mathrm{Cu} / \mathrm{Au})$ contact layer as it is shown in figure 2 .

\section{Results And Discussion}

The front TCO passivation effect of absorber layer major dependence is not shown but it is realized critical with thickness. The $\mathrm{SnO}_{2}$ and $\mathrm{ZnO}$ as TCO layer layer the significant variation of $\mathrm{FF}$ is realized however, Jsc is shown to vary in opposite trend. The $\mathrm{FF}$ for $\mathrm{SnO}_{2}$ is shown very low in comparison to $\mathrm{ZnO}$ 
emitter layer optimized thickness and electrical properties are analyzed. The variation of CdSe and CdS emitter is also shown less significant. CdSe emitter Jsc is increased while CdS emitter Voc is increased. The band gap of $\mathrm{SnO}_{2}$ is greater than $\mathrm{ZnO}$ and the electron extraction for $\mathrm{ZnO}$ is more preferable than $\mathrm{SnO}_{2}$ due to barrier effect [10]. Therefore, the FF variation is perceived. The back surface field contact design for electrical performance and back metal contact significance is widely analyze in this study. Ptype ZnTe as buffer passivation, conductive property and thermoelectricity perspective are influential. Increasing ZnTe BSF thickness CdTe cell Voc and efficiency is increased. The majority carrier conduction is possibly increased with thicknes and the details are reported later.

\subsection{CdTe HJ electrical analysis}

The variation of current density for $\mathrm{ZnO}$ and $\mathrm{SnO}_{2}$ TCO layer for diverse thickness of $\mathrm{CdSe} / \mathrm{CdTe} \mathrm{HJ}$ cell is reported. $\mathrm{ZnO}$ greater thickness is shown to decrease short current density whereas it is increased with $\mathrm{SnO}_{2}$ as it is shown in Fig. 3.

The thinner $\mathrm{SnO}_{2}$ layer lowest $\mathrm{Jsc}$ is realized but increasing $\mathrm{SnO}_{2}$ thickness the current density is shown to increase a bit whereas current density is decreased with increasing ZnO layer thickness as shown above. The band gap of $\mathrm{SnO}_{2}$ is higher than $\mathrm{ZnO}$ so the transparency of greater thickness of $\mathrm{SnO}_{2}$ comparison to $\mathrm{ZnO}$ is obvious. However, $\mathrm{FF}$ is not shown promising for $\mathrm{SnO}_{2} \mathrm{TCO}$ layer and $\mathrm{Voc}$ is shown lower for $\mathrm{CdSe}$ in contrast to $\mathrm{CdS}$ emitter. The $\mathrm{ZnO} / \mathrm{SnO}_{2}$ and $\mathrm{CdSe} / \mathrm{CdS}$ band gap and $\mathrm{Voc}$ of $\mathrm{CdS} / \mathrm{CdTe} \mathrm{HJ}$ is shown below Figure 4 (a) and (b).

Due to ZnO TCO the trend of increasing of Voc with TCO thickness. The effect of ZnTe back buffer on Voc is investigated. It is revealed that the back barrier thickness is influenced on electrical performance of CdTe cell. In our study the variation of ZnTe thickness is sensibly increased Voc. It is possibly due to the buffer contact to adjust the barrier between CdTe and metal back contact results in increase Voc and efficiency. But optimized ZnTe layer with diverse metal back contact the Voc and FF is reported later. The open circuit voltage, $\mathrm{Voc}=0.9757 \mathrm{~V}$ and efficiency $19.92 \%$ is achieved for $90 \mathrm{~nm}$ of ZnTe BSF thickness as it is shown in Fig. 5.

The current density and FF of CdS/CdTe HJ cell with diverse thickness of ZnTe layer is shown below Fig. 6 (a) and (b). The trend of decreasing of both FF and current density are observed with increasing ZnTe thickness though it is less significant.

\subsection{CdTe back metal contact electrical effect analysis}

Metal work function $\left(\mathbb{}_{m}\right)$ is greater than the work function of semiconductor. Due to contact the electrons from the active layer can be tunnel into the metal thus BSF barrier effect is potential for band bending so electrons moving back from metal to semiconductor.

$$
\emptyset_{B}=\varnothing_{m^{-}} \chi
$$


$\square_{B}$ is the barrier height is determined by the metal barrier, $\mathbb{\Xi}_{m}$ and the electron affinity, $\chi$. Two different metals Copper (Cu) and Molybdenum (Mo) are engaged with ZnTe BSF to study the electrical and optoelectrical (EQE) analysis.

Table 1

The output for different metal back contact used

\begin{tabular}{|lrllll|}
\hline \multicolumn{2}{|l}{ Metal work function $\left(\mathbb{\Xi}_{\mathrm{m}}\right)(\mathrm{eV})$} & $\operatorname{Voc}(\mathrm{V})$ & $\mathrm{Jsc}\left(\mathrm{mA} / \mathrm{cm}^{2}\right)$ & Fill Factor & Efficiency \\
\hline Copper $(\mathrm{Cu})$ & 4.7000 & 0.8790 & 24.16 & $84.75 \%$ & $18.0 \%$ \\
\hline Molybdenum (Mo) & 4.7600 & 0.9390 & 24.16 & $84.60 \%$ & $19.4 \%$ \\
\hline
\end{tabular}

Table 1 shows diverse electrical output of CdTe PV for two different back metal contacts. As it can be seen from the table, increasing metal work function has increased the Voc and efficiency. Mo highest melting point whereas copper high thermal conductivity is attractive. $\mathrm{Cu}$ is much cheaper and more easily obtainable than Mo. Between these two metals Mo yields energy output or higher efficiency is understood. The electrical performance of opto-electrical materials is critically related to the QE. To validate the data for Mo and Cu back metal contact of CdTe thin film solar cells QE is studied as it is shown in Fig. 7. The EQE of a device is the key parameters to determine its opto-electrical performance. EQE of conventional CdTe and the designed optimized CdTe solar cell using both Mo and Cu back contacts are demonstrated. The dotted line shows the maximum theoretical quantum efficiency and green line of both figures for convention cell EQE. The blue line of Fig. 7 (a) for Mo back contact and the turquoise line for Cu back contact is shown in Fig. 7 (b). Around $550 \mathrm{~nm}$ the EQE is realized highest and it is about $82 \%$ for Mo and $80 \%$ for Cu metal contact. Beyond that wavelength QE is gradually decreased and at $870 \mathrm{~nm}$ it is sharply reduced to zero. The variation of conventional and optimized cell EQE is clearly observed.

The optimized model and layout is shown in Fig. 8. Voc is shown to increase with ZnTe thickness which is resembled that the $\mathrm{p}$-CdTe majority carrier conduction is increased until certain thickness while minority carrier is suppressed to recombine. It is possibly due to the effective band barrier of minority carrier by ZnTe material and this barrier may improve thermal stability. The effective barrier at the back for CdTe solar cell is eventually improved the open circuit voltage. However, the Jsc, for the optimized cell is shown to decrease for both metal contact and Voc is decreased for Cu contact while FF is increased. Efficiency of solar cell is depending on Voc, Jsc and FF. Since the relatively greater passivation layer thickness increases the majority carrier transport and conduction thus Mo metal and ZnTe BSF contact has optimize the FF. Due to lessening of current density the efficiency is not significantly increased. Both TCO and ZnTe buffer thickness impact on carrier generation and majority carrier accumulation whereas work function of back metal contact is declined Jsc [11]. However, the Voc, FF and efficiency is realized to increase even at low work function metals contact that is the key consideration of CdTe TF numerical 


\section{Conclusion}

SCAPS Software based CdTe HJ PV cells utmost Voc and efficiency is numerically analyzed. The back contact passivation effect of $90 \mathrm{~nm}$ ZnTe BSF layer is presented to progress CdTe open circuit voltage, Voc $=0.9757 \mathrm{~V}$ and $19.92 \%$ efficiency. The increment of BSF layer thickness results in increased Voc, FF and efficiency. Efficiency upsurge till certain thickness of ZnTe isn't clear yet however, CdTe cell Voc, FF and efficiency are revealed to increase considerably due to ZnTe BSF contact and ZnO TCO and CdS buffer apposite thickness. In contrast to $\mathrm{SnO}_{2}$ TCO layer the $\mathrm{ZnO}$ layer better Jsc and FF is perceived. In order to improve efficiency, TCO and emitter of profound optical design is likely to progress optical absorption whereas ZnTe as BSF and metal contact is increased majority carrier conduction. Thus highest $85.4 \% \mathrm{FF}$ at $82 \%$ outmost EQE is achieved. Compared to $\mathrm{Cu}, \mathrm{Mo}$ is shown better of electrical output however, back metal contact is granted that the barrier adjustment between CdTe and the metal is the key to optimize Jsc thus; higher work function metal is desired.

\section{Declarations}

\section{Acknowledgements}

First of all I would like to thanks UMS for supporting me SDK0311-2020 grant allocation. This work is supported by UMS open access publication priority program.

\section{Author contribution}

Authors of this manuscript have contributed in diverse ways to make it success. One collaborative author from other institutes has contributed significantly to provide efforts for improving content whereas the same institute co-authors have contribution in literature search and figures redrawn.

\section{References}

1. Ghosh, B.K., Saad, I., Teo, K.T.K. and Ghosh, S.K., 2020. mcSi and CdTe solar photovoltaic challenges: Pathways to progress.Optik, p.164278

2. https://www.ise.fraunhofer.de/content/dam/ise/de/documents/publications/studies/PhotovoltaicsReport.pdf

3. Allen, T.G., Bullock, J., Yang, X., Javey, A. and De Wolf, S., 2019. Passivating contacts for crystalline silicon solar cells. Nature Energy, pp.1-15.

4. Mohamed, H.A., 2013. Dependence of efficiency of thin-film CdS/CdTe solar cell on optical and recombination losses. Appl. Phys., 113(9), pp.093105.

5. Liyanage G. K., Phillips A.B., Alfadhili F.K.,. Ellingson R. J, Heben M. J., 2019. The Role of Back Buffer Layers and Absorber Properties for $>25 \%$ Efficient CdTe Solar Cells. ACS Appl. Energy Mater.2019 (28), pp. 5419-5426 
6. Duenow, J.N. and Metzger, W.K., 2019. Back-surface recombination, electron reflectors, and paths to $28 \%$ efficiency for thin-film photovoltaics: A CdTe case study. Journal of Applied Physics, 125(5), p.053101.

7. Shen, K., Wang, X., Zhang, Y., Zhu, H., Chen, Z., Huang, C. and Mai, Y., 2020. Insights into the role of interface modification in performance enhancement of $\mathrm{ZnTe}$ : Cu contacted CdTe thin film solar cells. Solar Energy, 201, pp.55-62.

8. Wolden, C.A., Abbas, A., Li, J., Diercks, D.R., Meysing, D.M., Ohno, T.R., Beach, J.D., Barnes, T.M. and Walls, J.M., 2016. The roles of ZnTe buffer layers on CdTe solar cell performance. Solar energy materials and solar cells, 147, pp.203-210.

9. Dey, M., Dey, M., Matin, M.A. and Amin, N., 2015, September. Design of high efficient and stable ultrathin CdTe solar cells with ZnTe as a potential BSF. In 2015 3rd International Conference on Green Energy and Technology (ICGET)(pp. 1-4). IEEE.

10. Ghosh BK, Biswas TK, 2019; Emerging solar cell energy trade-off: Interface engineering materials impact on stability and efficiency progression, Int J, Engrgy Res. 43(5) 1670-1788

11. Haddout, A., Raidou, A. and Fahoume, M.,. Influence of the layer parameters on the performance of the CdTe solar cells. Optoelectronics Letters, 2018, 14(2), pp.98-103.

\section{Figures}




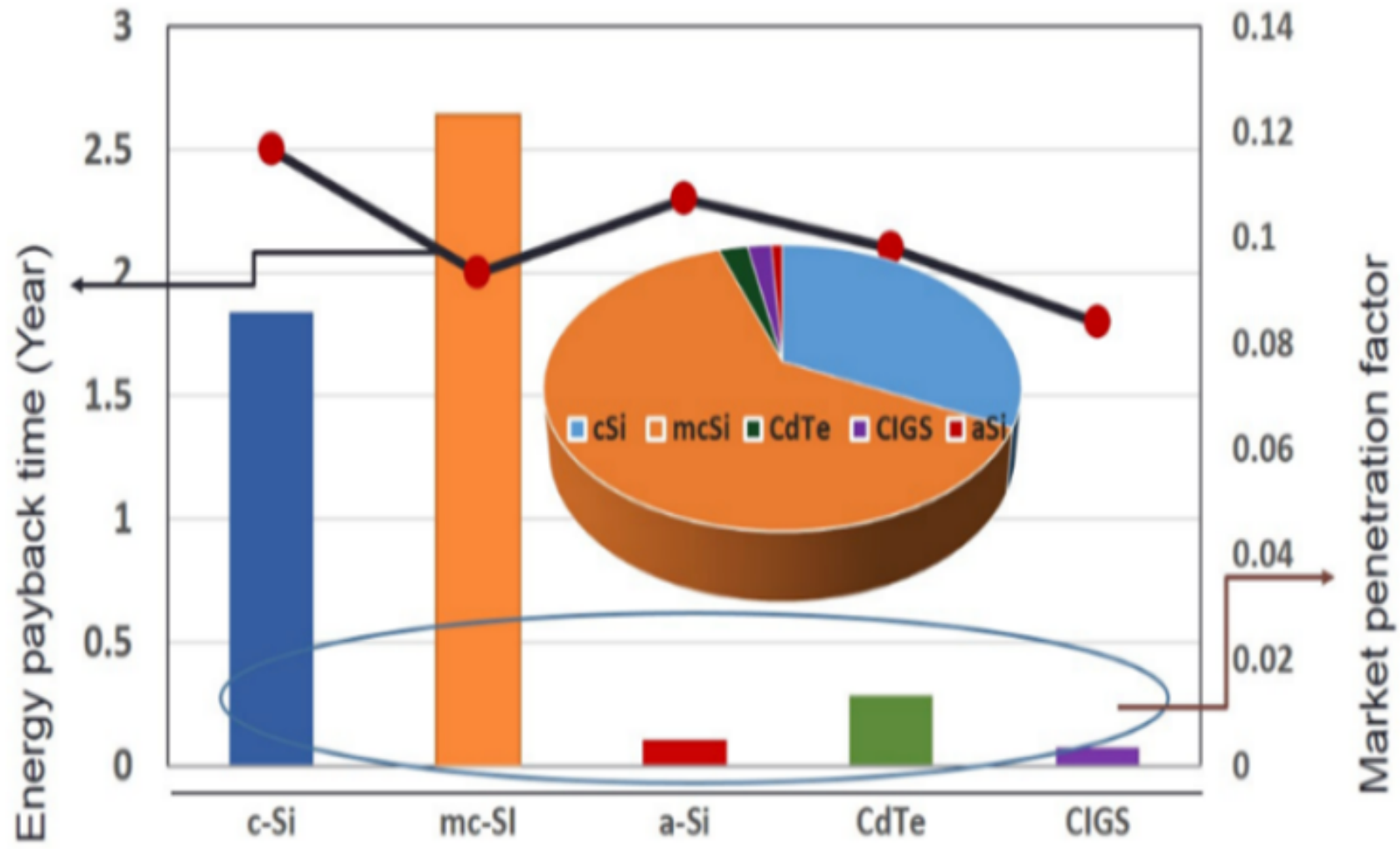

Figure 1

Different type's solar cells materials market (data from Fraunhofer ISE 2018 [Ref 1]) 


\title{
Front Contact: Transmission Solar Glass
}

\section{Buffer Layer: $\mathrm{ZnO} / \mathrm{SnO}_{2}$}

\author{
Emitter: CdS/CdSe
}

\section{Absorber: Cadmium Telluride (CdTe)}

\section{BSF: Zinc Telluride (ZnTe)}

\section{Back Contact: Mirror}

Figure 2

The design layout of Si HJ-IBC model and CdTe HJ solar cell

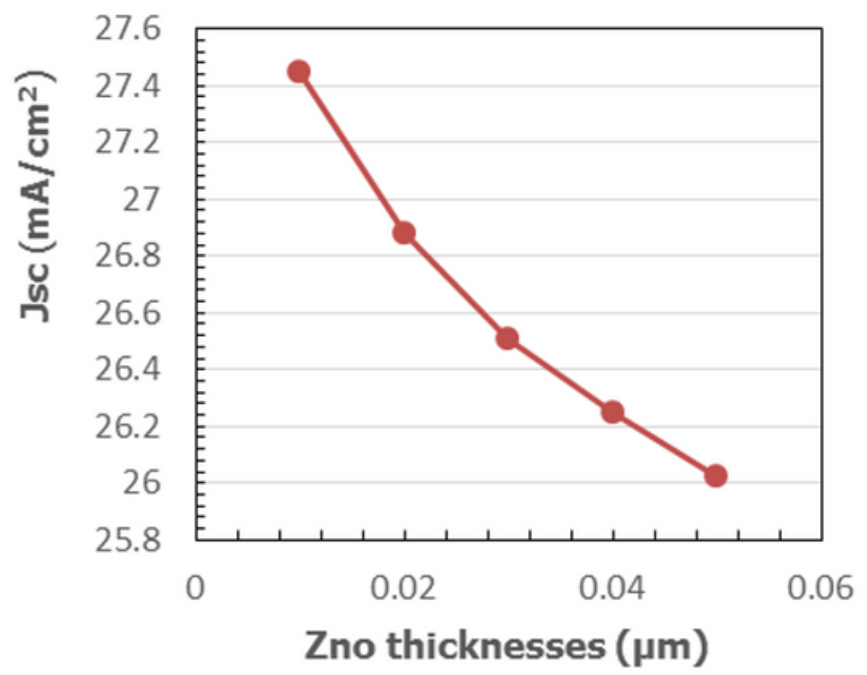

(a)

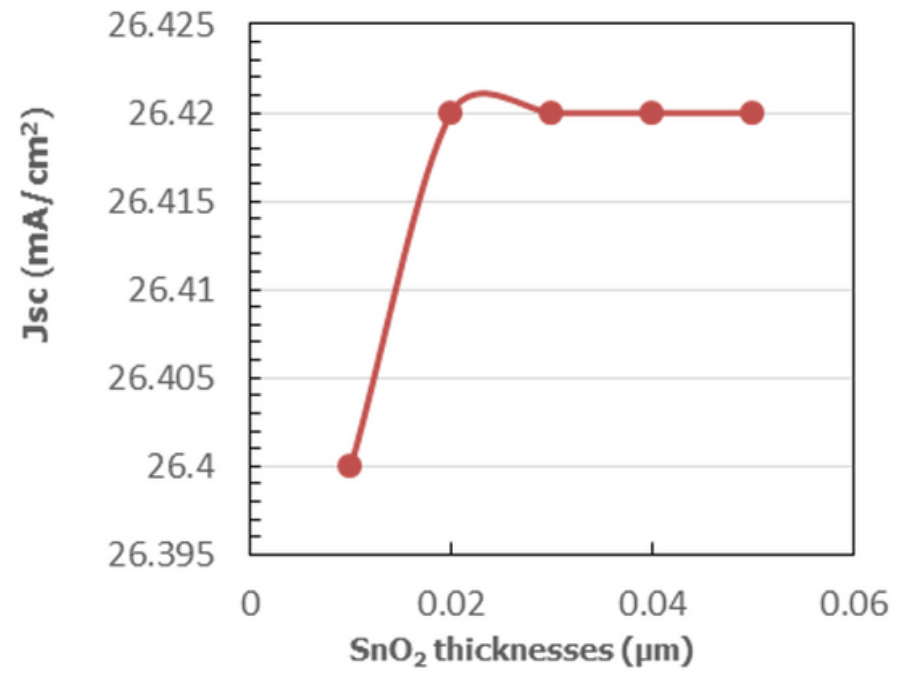

(b) 
The variation of short circuit current density, Jsc for CdSe/CdTe cell with ZnO (a) and SnO2 TCO layer thickness

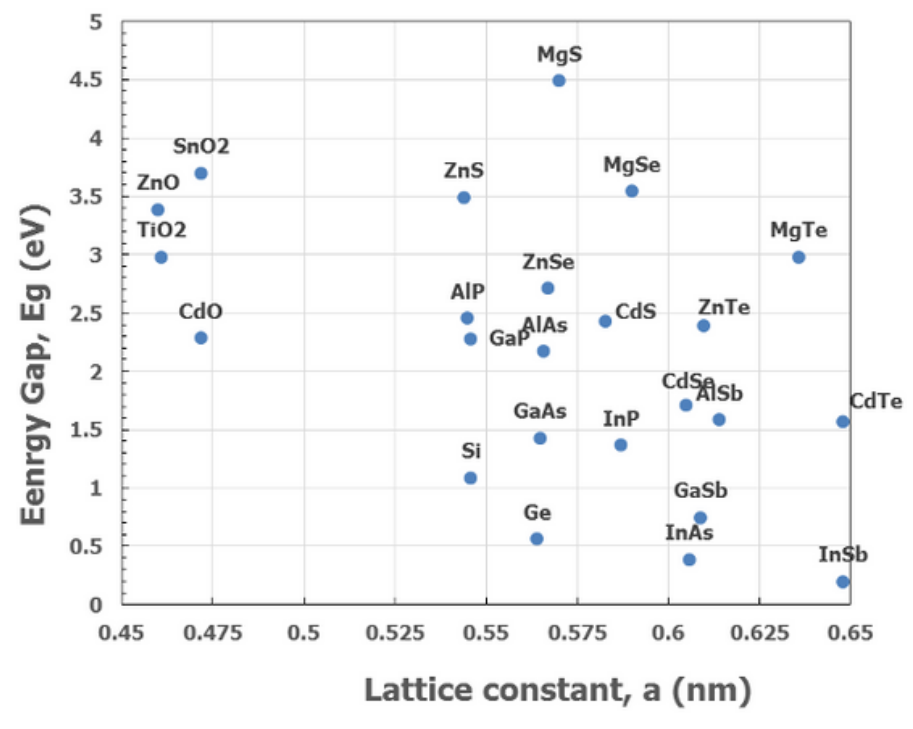

(a)

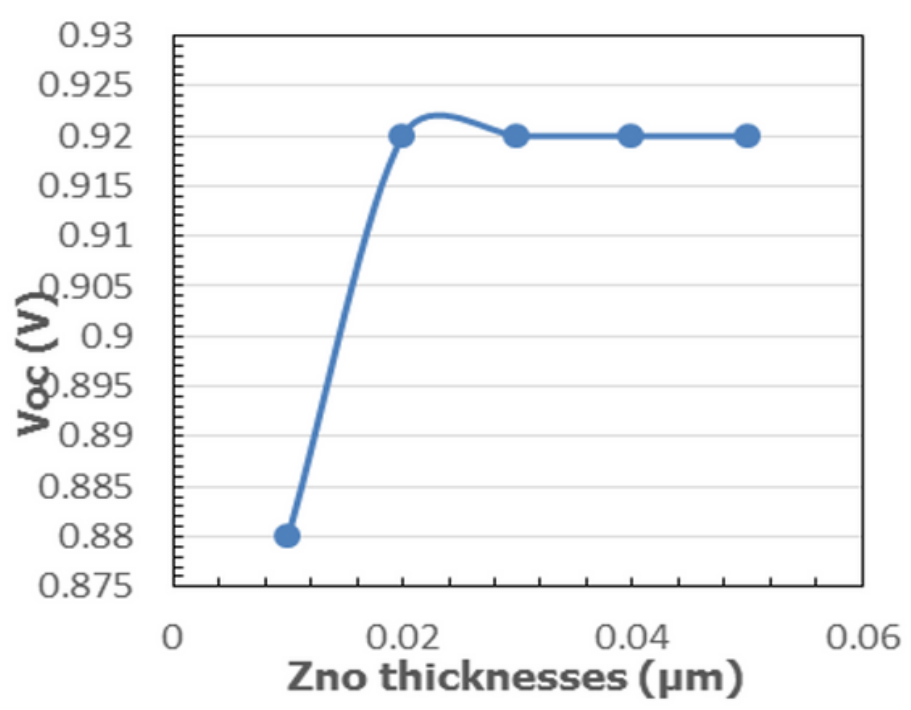

(b)

\section{Figure 4}

Semiconductors Voc vs lattice constant (a) and Voc of CdS/CdTe HJ for ZnO TCO (b)

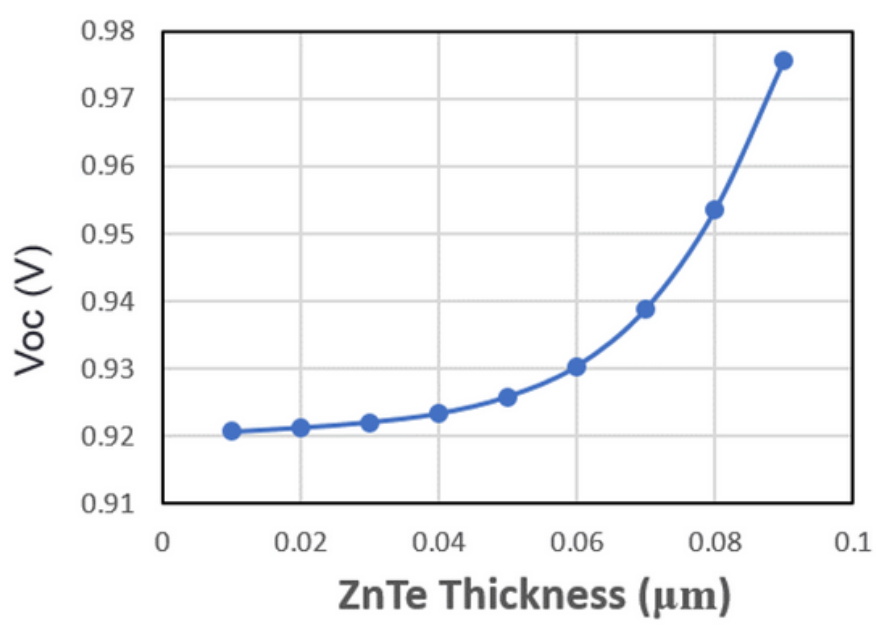

(a)

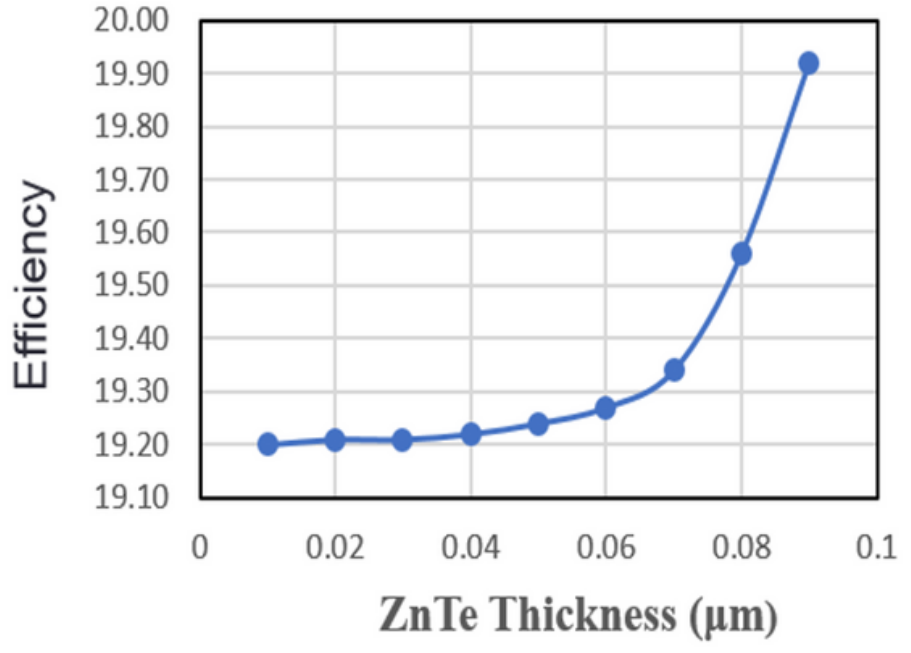

(b)

\section{Figure 5}

The variation of open circuit voltage (a) and efficiency (b) with ZnTe BSF contact thickness 


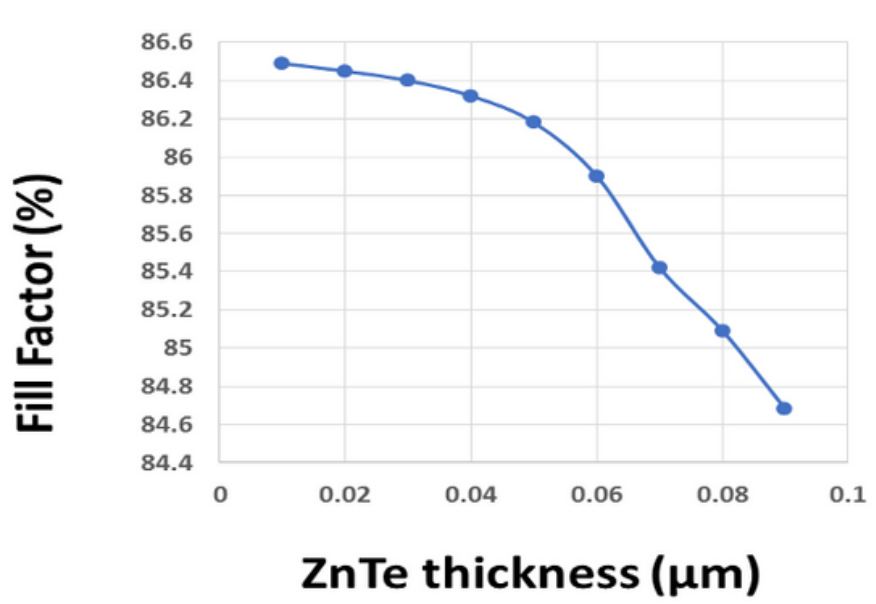

(a)

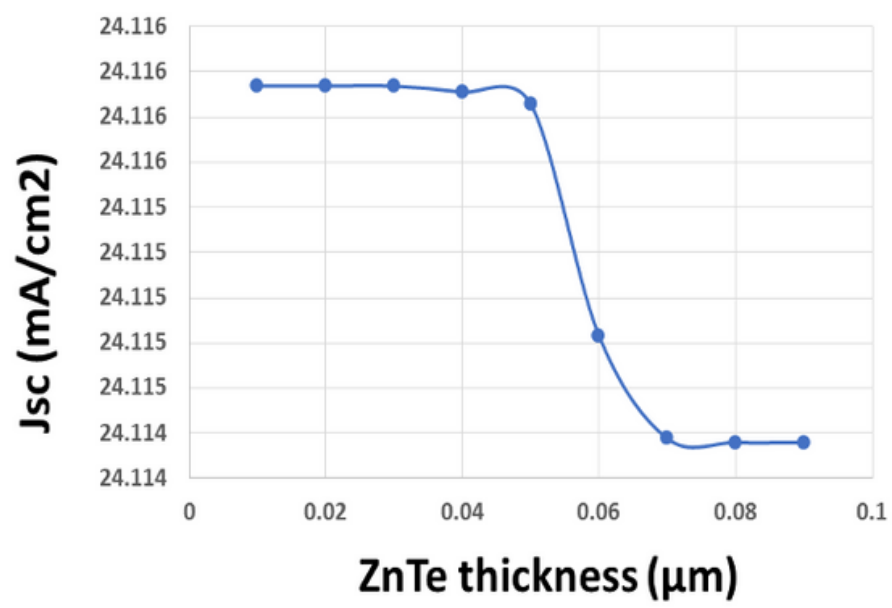

(b)

Figure 6

The variation of fill factor (a) and current desnity (b) with ZnTe BSF contact layer thickness
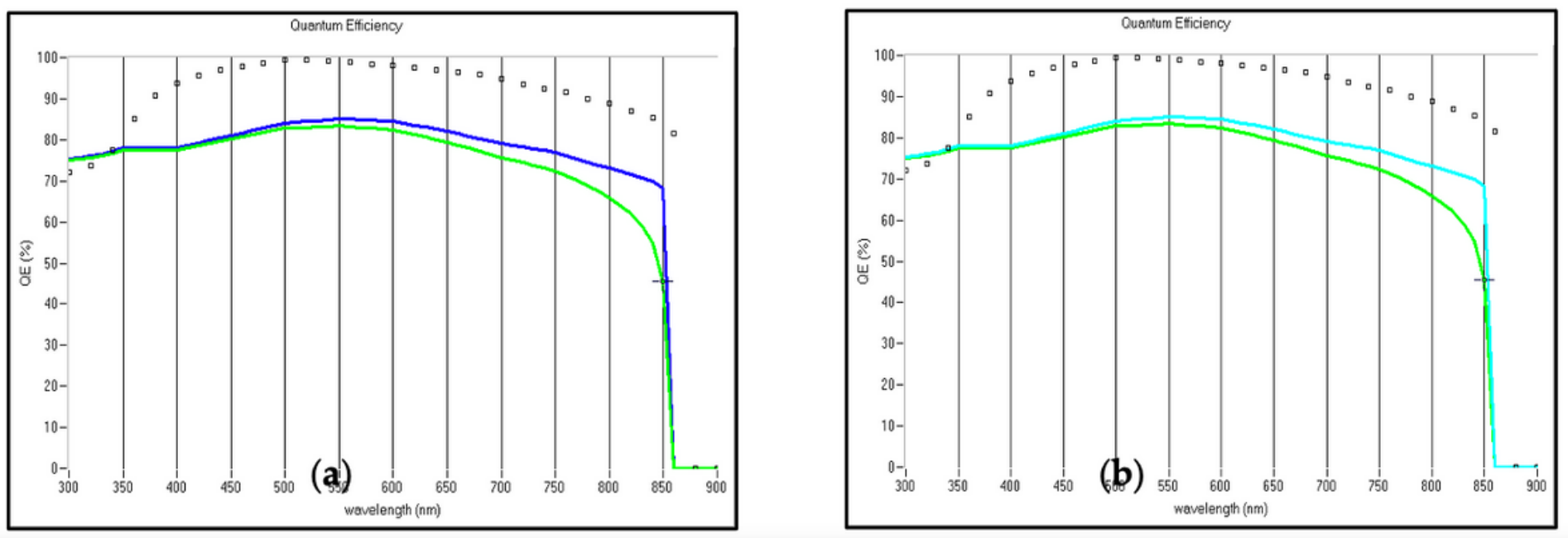

Figure 7

The quantum efficiency graph for conventional CdTe cell (below- green line of both figures); the Mo contact of (a) and Cu contact (b). 


\section{Radiation for sunlight}

\section{Solar Glass}

\section{$\mathrm{ZnO}$}

CdS

\section{CdTe}

\section{$\mathrm{ZnTe}$ Metal}

Figure 8

The final model of CdTe thin film solar cell

\section{Supplementary Files}

This is a list of supplementary files associated with this preprint. Click to download.

- GraphicalAbstract.png 